\title{
POÉTICA DE LA NUBE Y LA DUNA
}

\section{Antonio DOMÍNGUEZ REY}

Universidad Nacional de Educación a Distancia (UNED)

intetizamos en este estudio cierta aspiración radial de la poesía de Andrés Sánchez Robayna.
Nos centramos para ello, y a título introductorio, en dos poemas contiguos de La sombra y la
apariencia (2010). Son «Una rama de olivo sobre el agua» y «El vilano» (2010: 147; 149). Sirven de preámbulo y muestra de un proceso notorio y efectivo en la escritura del poeta. Es recurso interno de objetivación poética del lenguaje. Funciona a la par del significante pictórico asociado al lingüístico y dentro de una tradición milenaria - China, Grecia, Edad Media, Barroco - que adquiere resonancia con el simbolismo moderno, sobre todo desde Mallarmé y Baudelaire en poesía.

El primer poema resume lo que podríamos denominar ars combinatoria del poeta. Una octava de dos cuartetas con rima asonante e- $o$. La rima es más bien esporádica en la poesía de este autor, casi una anécdota al lado de otros recursos y figuras diseminadas dentro de versos y poemas. El tercer y cuarto versos son heptasílabos. El resto, de once sílabas.

\footnotetext{
UNA rama de olivo sobre el agua. Flotaba sobre el filo de onda y viento, junto a mi cuerpo. El sol daba en los montes secos.

Sobre el mar, en el filo de agua y aire, llegó una paz, de pronto, bajo el cielo. El agua silenciosa. Alcé la rama en el filo final de cuerpo y tiempo.
}

Esta alternancia de posibles hemistiquios del endecasílabo a modo de versos autónomos es una combinación frecuente en la poesía española de posguerra. Dota de movimiento interno al poema procurando cierta asimetría en consonancia con períodos psicológicos de emoción o contrapunto del campo conceptual instaurado. Los heptasílabos del primer poema contienen una contraposición léxica y de planos semánticos. Al recorte métrico le corresponde una tensión semántica. Frente al «cuerpo» o sobre él, el «sol», en consonancia con el «agua»y los «montes»: abajo y arriba, en la horizontal flotante del primer verso y al lado del cuerpo del poeta indicado por el posesivo «mi». El tiempo imperfecto — «lotaba»— y la preposición «sobre» acentúan la horizontal descrita, que también alarga la forma verbal «daba», aunque el «sol» pique «en los montes secos». Este adjetivo, 
«secos», contribuye a la tensión semántica creada en conjunción con el encabalgamiento y la sílaba métrica aguda del «sol» colgando al final de su verso.

La «rama» ondula además «sobre el filo de onda y viento», es decir, otra conjunción de elementos adjuntos entre sí por azar de circunstancia. Es ella quien fija el «filo», palabra que se repite dos veces más en la segunda estrofa. Una entre «agua y aire» y otra, en el último verso, como «filo final de cuerpo y tiempo». Las modulaciones son mínimas: «onda» por agua, primero, y «aire» por «viento», después. La variante remática la introduce el sexto verso — segundo de la segunda estrofa - y con implicación simbólica ya contenida en los sustantivos diseminados: «llegó una paz, de pronto, bajo el cielo». La «paz» corresponde al «olivo», y en el «cielo» se mueven «viento»y «aire». Apenas existe progresión temática. Sí se refleja, no obstante, una moción psíquica de matiz emotivo luego también conceptual. El verso es trimembre e induce acontecimiento asimismo modulado, como la «rama» entre «onda y viento» o «agua y aire». La forma indefinida «llegó» anuncia algo súbito — sexta y séptima sílabas del endecasílabo: «pronto»- y a la par también implícito en la «rama», pues la «paz» siempre se asoció al «cielo»y al «cuerpo». Todo acontece además dentro del «agua silenciosa». Agua de «mar», algo inesperado para una rama de olivo, como si una corriente fluvial la hubiera traído o alguien la arrojara en algún lugar entre las olas con intención asimismo simbólica.

Las repeticiones léxicas del análisis dan idea de la rotación semántica y tagmémica de los vocablos en torno a una imagen concreta. Este recurso combinatorio acentúa la interrelación de rasgos semánticos y el valor simbólico del lenguaje empleado. El cuerpo es otra onda al sol del mar último, final e inminente, del tiempo. Y así el poema: gesto alzado en la transición de la vida. Su verdadero tema, implicado, plegado, es la temporalización: «cuerpo y tiempo». La Körperlichkeit fenomenológica en modo Leib o carne sentiente que funde espacio y tiempo en la movilidad apenas notada, pero incesante, del transcurso humano en el cosmos.

El segundo poema, «El vilano», consta solo de cinco versos también distribuidos - tres y dos- en dos estrofas. Aquí se combinan pentasílabos y un heptasílabo —el segundo verso - en la primera estrofa. Y hasta segundo, heptasílabo, y tercero, de cinco sílabas, forman endecasílabo si los juntamos:

$$
\begin{aligned}
& \text { SÓLO tu sombra } \\
& \text { pesa menos que tú } \\
& \text { sobre la tierra. }
\end{aligned}
$$

Aún menos que tu sombra,

nuestro paso en el polvo.

La brevedad de la forma se ajusta asimismo a la implicación semántica del tema: escaso peso del tránsito vital comparado con la sombra del vilano. El valor poético reside aquí en la agudeza de la imagen obtenida por comparación y compresión de formantes. Y ello también con repeticiones léxicas directas, deícticas («sombra»), o indirectas («paso», «tierra», «polvo») o de marcadores oracionales, en apariencia prosaicos: «menos que tú». La acción es mínima, pero sugerente. Las 
repeticiones fónicas la sensibilizan: valores deslizantes del sonido [s], y compactos de las oclusivas. El carácter plástico del significante es recurso casi continuo en la escritura de este poeta ${ }^{1}$. Corporeíza la dicción sonora al tiempo que refuerza, con ella, la encarnación semántica, el sonido y el significado en unidad simbólica de sentido. Y así objetiva el poema como nuevo fenómeno de existencia.

\section{Reescritura literaria}

En este texto apreciamos mejor, por la forma y el paralelismo de imagen, el efecto de haikú que tienen algunos poemas de Sánchez Robayna. Las dos muestras sintetizan la búsqueda de su poética. Se resume ésta en un conjunto léxico combinatorio con modulación replicada: la ars anunciada al comienzo de este estudio. O dicho con otra perspectiva, la modalidad de un cómo perceptivo subyacente, o declarado, tiende a circuir el léxico y el significante sintáctico en maclas que acumulan valores semánticos. Por eso se ha caracterizado esta creación poética de esencial. Y la esencia corresponde más bien a la objetivación fenoménica del lenguaje. La búsqueda de una identidad diseminada entre los elementos del poema. Y de aquí el salto a poesía metafísica, declarado por el mismo autor en varias ocasiones. Es fácil interpolar implicación conceptual y trascendencia en textos breves de correlación sígnica intensa. Sánchez Robayna tiende una red siempre circunspecta de palabras cuyas transiciones proceden por alusión, elisión, sinestesias interpuestas y adjunción o superposición de paradigmas implicados por efecto de dislocación sintagmática, con o sin coupling, pero siguiendo un travelling perceptivo pendiente de la recepción lectora: sol, luz, roca, nube, duna, palma, fuego, línea, tinta, silencio - real o inducido - nada, mucha nada entre «la sombra y la apariencia». La poesía española se anonadó de repente con insistencia nadificante tras un vitalismo emergente: Hierro, Brines, Gamoneda... Todo poeta selecciona una tribu de nombres cuyo zumbido se extiende y dilata produciendo las celdillas del panal poema. Tales redes se disponen en virtud de campos conceptuales que van de lo visible a lo invisible, de lo aparente o sugerido a lo oculto, de lo sólido y duradero a lo efímero y caduco, del ser a la nada, o al revés, con inversión retórica. Y hay propensión a titular estos giros de tensiones trascendentes cifradas en términos como iluminación, revelación, metafísica, misticismo, y con resonancia de nombres ilustres de poetas significados, antiguos y modernos.

Sánchez Robayna suscribe una tradición selecta de la poesía de todo tiempo. Rinde tributo a la profesión literaria que ejerce como profesor universitario y al oficio de lector estimulado por una indagación expresiva que es, tras la inquietud y azar del hallazgo, momentánea complacencia creativa.

El conocimiento obtenido revela su propio límite: una docta ignorancia — Nicolás de Cusa - o la evidencia socrática de que el saber es siempre límite de lo aún desconocido. Vicente Aleixandre

\footnotetext{
${ }^{1}$ Hemos dedicado algunos estudios a los aspectos plástico, sígnico, semiótico, y fenomenológico de su poesía. Véase la bibliografía final.
} 
dejó huella de esta reducción existencial, y por épocas de la vida, en Diálogos del conocimiento (1974: 26): «Conocer es amar. Saber, morir», dice Él a Ella en la sección de «Los amantes viejos». Amor, vida, pensamiento fijo como la piedra. Y si hendimos ésta, su oscuridad compacta se vuelve aire. ¿Conocer, indagar la superficie? ¿Y qué le queda al hombre cotidiano? «Yo soy sombra en la sombra», afirma «El inquisidor, ante el espejo» (Aleixandre, 1974: 55). La revelación final del poema se detiene en Sánchez Robayna (2008: 344) ante el silencio de lo innominado: «la palabra se identifica o se asocia a lo desconocido, al inconocimiento». Ahí ya no hay nombre.

Esta afirmación parece respuesta al canon de la poesía del conocimiento que caracteriza a los poetas de los años 50, con José Ángel Valente en primer lugar, de cuya obra y actitud crítica se hace eco el poeta canario, a la par de Haroldo de Campos y Octavio Paz. Valente lo lleva a Lezama Lima y su visión simbólica del Barroco, así como al ensayo poético de María Zambrano. Octavio Paz le induce la alternancia cíclica y Haroldo, consumado traductor, el concretismo material del soporte silábico y gráfico — tinta—, como Mallarmé, del mundo y su transducción idiomática. La escritura dilata entonces el espacio y tiempo de la moción corporal, por una parte, de la conceptiva, por otra, y halla cuerpo en la imagen que cifra el poema. Dimensiones espaciales: lo abierto y circuido; dimensiones temporales: lo interno y externo. Y esta alternancia 'ecoa' el Espacio y Tiempo de Juan Ramón Jiménez, pero también la aspiración a lo Uno presente en poetas — San Juan de la Cruz-, filósofos como Parménides, Platón, Plotino, el Aeropagita y tradiciones herméticas de variado signo. El texto resulta entonces resonancia de una red múltiple o tela - textura - tejida con hilos que atraviesan los nervios ontológicos del espacio-tiempo-movimiento en la nervadura de En el cuerpo del mundo (2004), título que recuerda a la «Naturaleza Común de las Naciones», de Giambattista Vico, al «universo indefinido» de Francis Ponge y al «Congreso del Mundo» de Borges (Sánchez Robayna, 1983: 37-39)².

La gran metáfora del Renacimiento - el Libro del Mundo, de la Naturaleza - despliega sobre la página blanca la escritura, y ésta simboliza, con rasgos semánticos y conceptuales, las raíces esotéricas de los significados esparcidos en coreografía de reflejos, relaciones, superficies, volúmenes, una arquitectura que alza lo máximo en lo mínimo, difracta la unidad en fragmentos, o viceversa. El fragmento intensifica la unidad discursiva y confiere un halo casi absoluto a la frase. Rastro, entre otros autores, de Herder, Hamann, Nietzsche. El texto es también intertexto, trasunto y traducto, correlación de elementos, «signos en rotación», «corriente alterna» —Octavio Paz-, música cósmica, órfica, pitagórica, de cámara, contracta, extracta, diluida o en relieve; «transcreación»_-Haroldo de Campos (1981: 180; 1984: 240)—. El intertexto sigue la glosa en que se ha convertido la épica moderna con los Cantos de Ezra Pound, el cruce idiomático de James Joyce, y el interludio de prosa y verso de Thomas S. Eliot, o el filtro de la tradición con sus elementos nuevamente combinados. En esto consiste la «Impersonal theory» de Eliot (1980: 40): «the conception of poetry as a living whole of all the poetry that has ever been written».

\footnotetext{
${ }^{2}$ Son referencias de Sánchez Robayna en Tres estudios sobre Góngora (1983: 37-39). Este libro de ensayos contiene las claves metafóricas de su escritura.
} 
La poesía se autolee. Una lectura ya pancrónica a partir del binomio Góngora-Mallarmé, estudiado con atención por Sánchez Robayna, y con trasfondo pictográfico de Horacio: ut pictura poesis. Un remanente dirigido más a la asociación de las dos artes que al trasfondo horaciano, cuya simbiosis de poesía y pintura cifra una latencia fonémica y escritural del Renacimiento y Barroco. El poeta canario cita al Abad de Rute, lector de las Soledades de Góngora, quien lo incita a decir, recordando a Horacio: «la poesía en general es pintura que habla» (Sánchez Robayna, 1983: 46). La lectura deviene proceso simbólico que envuelve al autor, al lector y al Mundo intersticio: grafo : fono : concepto : icono. Es decir, pensamiento y escritura iconográficos, jeroglíficos, dramatizados. Y a Góngora se une Mallarmé con el trasfondo del simbolismo cifrando en el papel, la tinta y la materia del lenguaje, los colores diurno y nocturno del cielo, «l'intégrité du Livre» (Mallarmé, 1945: 373), hasta el claro-oscuro de la conciencia en el tintero: «L'encrier, cristal comme une conscience» (Mallarmé, 1945: 370). Algunos otros testimonios son suficientes para plasmar el absoluto poético y astral, coreográfico, de este autor: «La pièce écrite au folio du ciel» (Mallarmé, 1945: 214), dice el poeta francés refiriéndose al oficio de la crítica nunca semejante al fenómeno de la poesía, a la que califica además de «nature animée», «l'alphabet de la nuit», «des astres [...] noir sur blanc» (Mallarmé, 1945: 303, 370), etc. Es decir, El espíritu de la letra, con título ahora de Ortega y Gasset, también glosado por Sánchez Robayna (1983: 71-72), texto donde el filósofo madrileño recuerda el status nacens de la poesía, entre Góngora y Mallarmé (Ortega, 2005: 176), pero sin citar a Johann G. Hamann. La poesía del poeta barroco, comenta Ortega, «crece a la vez en dos sentidos opuestos — hacia el centro subterráneo y hacia las estrellas-, así la poesía de Góngora: la nube ‘culta' y el humus del realismo poético popular» (Ortega, 2005: 175).

Hamann ya había caracterizado los sonidos y las sílabas como formas a priori que cifran los elementos estéticos del conocimiento, aunque no les pertenece nada del objeto. Más bien lo crean, pues espacio y tiempo son matrices, y no ideas innatas, como en Kant, del conocimiento y de la razón (Hamann, 1999b: 286). En el habla, hay correlación de pensamiento y palabra, cosa y nombre, e imagen y signo. En resumen: pensamiento, cosa, imagen: palabra, nombre, signo. El organigrama de la modernidad de la raíz estética, es decir, poética: Aesthetica in nuce (Hamann, 1999a: 199). Asistimos a una búsqueda de la matriz creadora circunscrita en la profundidad del espacio-tiempo y las cualidades, extensas e intensas, los «campos pre-espaciales» de la constitución, «un existencial», dice Jean-Claude Maldiney (2012a: 20, 21). El fenómeno estético es advenimiento, algo que acontece viniendo al instante-lugar de la creación concreta (Maldiney, 2012b: 30). Y si acaece llegando - añadamos - se está haciendo. El acto poético engloba el proceso de conciencia. Hace: «The work does not only exist, it acts, it does», resume Jacques Maritain (1953: 357). Y hace, como toda belleza, por el hecho de ser: «to do as one is» (1953: 368).

Relectura del universo. Todo nombre remite a otro nombre en una cadena recursiva — generación sintáctica, combinación semántica — de secuencias, ritmos, estancias, vivencias. Al rechazo de la literatura adocenada - crítica de la poesía retórica de la época del poeta - lo sustituye la metaliteratura de otra tradición ya notable. Con una diferencia, sin embargo: se busca la 
manifestación de un sentido simbólico nunca estable, aunque la apariencia sea de unidad temática. Sánchez Robayna (1987: 97) llega incluso a negar esencia poética al encuentro de sentido, idea que titula un poema suyo con eco de Mallarmé y Octavio Paz: «El sentido del poema ha de ser destruido» ${ }^{3}$. Y se trata de lo contrario: obtener el sentido pleno de las palabras. El poeta busca, no afirma, dice Sartre (1986: 158) comentando a Mallarmé : «Le sens, au lieu d'être affirmé, sera découvert». Descubrir el sentido nuevo de las palabras de la tribu ensambladas en un orden también nuevo.

La pretensión de anular el sentido de las palabras es otra postura retórica de época, inducida por el funcionalismo lingüístico y derivaciones suyas como la deconstrucción y genealogía hermenéuticas de Jacques Derrida y Michel Foucault, aunadas por Henri Meschonnic en el signo del poema. Produce, creemos, un espejismo dudoso. La destrucción atañe más bien a los significados ya desnutridos de la tribu y su renovación poética. Lo desteñido, y no «destruido», es el significado mercantil del lenguaje. El poema revitaliza la expresión en virtud precisamente del sentido que lo procura como origen emergente de los vocablos que lo sustancian. El significado no es logaritmo de una ecuación semántica ni metaparadigma de secuencias superpuestas. Se devalúa porque pierde la energía del comienzo, fenómeno ya criticado por Fritz Mauthner y Nietzsche. A esto se refiere precisamente «La latencia sin fin de todo nombre» o búsqueda subyacente e inmanente de algo aún desconocido, del nombre interno, «el nombre conseguido de todos los nombres», como dice Sánchez Robayna en La sombra y la apariencia (2010: 37). Es el nombre justo, cifrado, al que aspiraba Juan Ramón Jiménez. La nominación absoluta de la Biblia, pero de glosa múltiple, como refleja Fray Luis de León en verso y prosa.

Los significados son, con todo, el asentamiento con o sin lugar estable del sentido que induce nueva lectura o exégesis una vez anclado en poema. Es efecto logogramático de la escritura, sea ésta anagrama o hipograma, en términos de Ferdinand de Saussure. Y esto presupone un punto, al menos, de referencia. Otra cosa es que tal punto o gramma remita a un desplazamiento continuo de ejes temáticos, referencias y perspectivas, elipses. Y la deslocación verbal, digamos forzando la raíz, por efecto de emergencia originaria indujo a considerar la poesía como alteración, desviación y hasta violación creativa que produce «un nuevo y separado orden», dijo Octavio Paz (1970: 11). La poesía de la desviación es tan técnica y retórica como el lenguaje amanerado del que huye y le sirve de referencia.

\section{Tensión objetiva del poema}

La reverberación combinatoria fluye en Sánchez Robayna a la par del orden perceptivo de la experiencia poética. Recurre a centros de anclaje objetivo. La apariencia de sin-lugar del lugar —un eco, conocido o no, de Emmanuel Levinas - es más retórica que efectiva, pues el poema contiene un

\footnotetext{
${ }^{3}$ Es título del último poema de Clima (1987: 97). Esta afirmación coincide, si no hereda, la visión crítica de Octavio Paz respecto del arte moderno: «Modern art is a criticism of meaning and an attempt to reverse the signs, an attack on meaning» (1970: 31-32).
} 
sentido coincidente, la mayor parte de las veces, con significados concretos. Es lo característico de los poemas isleños, dentro de una tradición también importante, barroca, modernista y de vanguardia, en poesía y pintura ${ }^{4}$. El léxico, lumínico y pétreo — Piedra de sol, Octavio Paz — gira en torno a un centro intuido (Sánchez Robayna, 2010: 123), cósmico aunque sea local: lo máximo concentrado en un punto expansivo (Nicolás de Cusa). La presencia deviene entonces trascendente, aunque trate algo inmanente como el mar, donde coinciden restos, la intuición de un origen diseminado en ellos, signos ya de una realidad transparente en lo opaco, radiada de ausencia, pero ideada, imaginada, el signo imaginativo que convierte las palabras en objetos, según Sartre y Levinas.

La realidad remite a un polo de significación ideada. Y esto es el envío de la significación como signo. La representación pliega las preposiciones - re, pre - de lo asentado y lo proyecta en una dimensión de imagen que es icono bastantes veces, dibujo, línea deslizada. Tiende a signo de unidad aunque haya sombra, la línea sea surco (Emilio Lledó), el tiempo vierta ácido y el instante resuma cuanto somos como punto de alianza en «lo abierto» (Sánchez Robayna, 2010: 119; 121; 145). Apertura del deseo hacia un vínculo de unión y hasta presencia intuida, más bien anhelada de Dios, por un momento (Sánchez Robayna, 2002: 69; 72; 74).

Cabe decir, por tanto, que la ars combinatoria modula el referente lenguaje como otro objeto de la naturaleza. Así lo afirma también Sartre de Mallarmé. La palabra como ser del mundo, con eco evidente, pretendido o no, en Sánchez Robayna (2002: 33). Y más que objeto, un objeu, en el sentido que Francis Ponge (1999: 784) otorga al poema, pero en nuestro poeta con alusión tanto medieval como surrealista a la española, afirmando la realidad sobrepuesta. A la tendencia objetiva la recubre otra objetal. La dinámica de significación intuye, no obstante, resquicios de acceso al interior del objeto, a su profondeur. Y no para sentir dentro la tranquilidad que Henri Michaux (1963: 9-10) advierte al querer entrar en una manzana, como nueva perspectiva de bodegón poético, situada encima de la mesa («Magie», de Lointain intérieur). Su interior se resiste y el esfuerzo deja al poeta helado. No basta ver el objeto, tocarlo, sentirlo. Hay que habitarlo. Beber incluso el libro — su tinta - como si fuera un cristal cuyo continente y contenido transparentan lo mismo que un vaso de agua, el «verre d'eau» de Ponge (1999: 583; 586; 608; 611). La profundidad intuida es la piel continua del mundo en la sucesión de espacio-tiempo dinamizado por más que se trate de la quietud de un objeto inmóvil, como una piedra, roca, o semoviente, como una duna. Lo visible es superficie lumínica, aunque esté en sombra, de lo invisible.

En este trasunto de continente espacio-temporal del contenido objetivado el como o cómo del modo sentiente perduran en la memoria sobre el qué sentido con doble función retórica, y al estilo de Wordsworth en El Preludio (1999: 63). El modo lo dicta el tono existencial de inscripción en la realidad suscitado por una fuerza visionaria («the visionary power») inducida a su vez por la moción

\footnotetext{
${ }^{4}$ Baste citar los nombres de Domingo Rivero, Alonso Quesada, Agustín Espinosa, poetas canarios estudiados por Sánchez Robayna. Y los viajes a las islas de André Breton, Jacqueline Lamba, Benjamin Péret, Jean Cocteau. La presencia de estos escritores en Canarias produjo cierta inclinación de vanguardia en poesía y pintura.
} 
y fortaleza del sonido natural y del afecto antes de su manifestación como forma o imagen. La mayoría de las veces despliega planos contiguos, adjuntos, superpuestos o imbricados de realidad. Así la poesía descriptiva, povemática ${ }^{5}$ o el proême (Ponge), la prosa lírica de Sánchez Robayna, como en «Breve meditación sobre la cal y el tiempo» de La sombra y la apariencia (2010: 231-232). Y la inclinación narrativa tiende a estancia en trasunto de una realidad interior o, como dice Wordsworth (1999: 63), «con un alma añadida, / una virtud no suya». El ánimo suscitado despierta el sentido y sentimiento de responsabilidad humana ante y en las cosas, aunque sea solo desde «la sensación de oscura similitud que une / nuestro mundo moral con las formas externas» (Wordsworth, 1999: 51). Este apego vinculante de la sensación lo intuye Wordsworth al recordar la hermosura surgida en su mente ante la inmensidad de la naturaleza. En Sánchez Robayna suscita también una moción de alianza, próxima al pacto vinculante que Octavio Paz reconoce en la poesía con trasfondo filosófico de Rousseau.

El alma de Wordsworth inquieta a Sartre cuando este describe el reflejo interno del signo pictórico y poético, en principio, y a diferencia de la prosa, opaco, pero al que transparenta la cualidad de la materia y «una pequeña luminosidad propia» (Sartre, 1948: 13; 19-40). Esta luz convierte a la palabra de uso en imagen aspectual y especular del mundo a través de la significación encarnada en la materia plástica del lenguaje. Se produce entonces un espejismo de objeto compacto y, a la vez, transparente, como sucede con el «vaso» de Ponge. Tal intención es germen cristalizante en varios poemas de Sánchez Robayna. Y aunque esto suena bien, extremado supone un «suicidio poético», como en el caso de Mallarmé, augura Sartre (1948: 159). El encantamiento de las palabras, la oblicuidad de la sugerencia barroca, mallarmeana, es algo imposible para el escritor y pensador existencial francés, pues si hubiera tal luz en la realidad, existiría transcendencia, don, y entonces palabra vinculante para el hombre. Creer es confundir las cosas con sus nombres, concluye Sartre (1964: 209).

\section{Un pliegue crítico de escritura}

La otra dimensión del como y epigénesis descriptiva de un fenómeno autobiográfico, directo o indirecto, introduce en el poema un relato contextual. La imagen se explicita y el trazo de escritura se detiene en lo narrado, con efecto de povema o tensión lírica suscitada por los detalles de la vida. En tales casos, el recurso a la naturaleza suele funcionar, según reflexiona Sartre agriamente, como pretexto para verse reflejados en ella y a nosotros mismos como otro polo suyo. Y en la mismidad — añadamos - actúa el lenguaje con reflejos plegados, entre ellos el yo del poeta, arista y canto del pliegue. La visión concertada e idílica de la naturaleza y del sujeto cognoscente la quiebra el existencialismo nihilista, pues la escritura simbólica de las cosas en la piel y retina humana ya no es significativa, como afirma Ponge (1999: 647).

\footnotetext{
${ }^{5}$ La noción de povema refiere el discurso dentro del poema, a modo de relato lírico. Cf. Antonio Domínguez Rey (1987: 13).
} 
La escritura de Sánchez Robayna dilata entonces la síntesis y sintaxis compacta de los textos mínimos o de la imagen doblada. Es la tensión entre la energía del sonido natural antes citado en Wordsworth y aquel poder visionario trascendente, pero ahora plastificado en reversión sobre sí y con efecto de imagen sartriana. El deslizamiento de la forma se replica y este movimiento sugiere un automatismo que idealiza el fenómeno poema. Levinas lo critica y rechaza su espejismo en el arte occidental por convertir la transitividad alterativa en forma alter ego del otro o tú que es el yo artístico creyendo que fundamenta la intersubjetividad del género humano ${ }^{6}$. Y esta trampa de autocomplacencia poemática se superpone al hecho de perspectiva en tú del yo poético. Así acontece en bastantes poemas, autobiográficos o no, de Sánchez Robayna. Es, por otra parte, recurso usual del espacio interno o monólogo lírico de la poesía del siglo XX tras las dos grandes guerras europeas y la civil española.

Tal fenómeno acontece dilatando el eje yo-objeto con la doble referencia de lo circuido en ese encuentro o de una situación recuperada por la memoria, como si asistiéramos a un relato o noticia recreada de lo ya vivido. Y así desde el legado de Marcel Proust. Tal recuperación alcanza valor de símbolo. La escritura labra un proceso y surge entreverada con sentido de relieve o escultura fluida del ánimo. Recude sobre sí, diría Levinas. Dibuja un eje transversal en los poemas más sintéticos de Sánchez Robayna.

Esta tendencia la advertimos en textos como «Una piedra, memoria», «Una hoguera y el centro de la muerte», «Una luz, ante la casa», de Fuego Blanco (1992: 89-91), y se plasma en El libro, tras la duna. Suele darse en la tensión de la realidad como signo de emoción o trasunto de una vivencia, de otra latitud nacida ahí, en ese momento, y cuya existencia es el poema. Latitud entrevista en la distancia del guión yo-objeto (mundo), con pausa o marca de inscripción —a veces, de vacío-, tal el efecto en bastantes poemas del libro así titulado, Inscripciones (Sánchez Robayna, 1999: 96-99).

La visión intersticia del eje povemático suele estar fijada con una incisión, cisura y cesura, pero también circuncisión reflejada en los títulos por una coma. Como en «Signo, vacío», de Fuego blanco, y otros poemas. Refiere el vacío que acusa Sartre en el proceso metafórico de Mallarmé al sustituir el objeto referido por otro de lenguaje. Esa coma es corte, elipsis que adjunta dos planos en distancia relatora compacta, pues coma puede equivaler a dos puntos, verbo atributivo o predicado, o ser simplemente señal icónica y apelativa, hasta fática, de una aposición que no halla signo claro de equivalencia. La coma refiere entonces el rasgo, más bien trazo de una yuxtaposición pictórica o incluso la eliminación, el borrado de materia que el golpe escultórico induce revelando la forma

\footnotetext{
${ }^{6}$ Levinas afronta la cesura y cisura instaurada entre el esquema fenomenológico de la imaginación y la distancia ontológica del lenguaje convertido en imagen objetiva de una realidad fluyente. La imagen es no-objeto y se funda en una semejanza que presupone hiato entre los atributos, cualidades del ente y su identidad. Tal semejanza indica, antes que relación de polos, el proceso en el cual se conforman. La imagen salta sobre el intervalo de atribución como si resbalara en una superficie lisa erosionándola. Por eso, el ritmo es para este filósofo francés tiempo en imagen. El inciso e intervalo ya se conforman en la sensación al plegarse con rasgos de permanencia. El ser escapa de sí alterándose al verse reflejado en los atributos que lo definen. Y la alteración lo sigue como sombra suya. Cf. Levinas (1994: 131; 133; $134 ; 136)$.
} 
naciente en el bloque de escritura. Este uso de la puntuación refuerza el modo objetivante y sintético del poema.

El efecto de añadir elidiendo, y hasta borrando, va más allá de lo que quiso simbolizar el tachismo en pintura, escultura y poesía, con ejemplos claros en el entorno poético de Sánchez Robayna y otros buscados por afinidad estética de paratexto. Nombres como los de Ullán en poesía; Tàpies, Miralles, Ràfols-Casamada, Sicilia, el también poeta y pintor Manuel Padorno, en pintura; Oteiza, Chillida y Chirino en escultura. Podríamos extender la lista a músicos célebres del postmodernismo, como Cage, o Stockhausen. El borrado de sonido de Stockhausen indaga «formas negativas» en el hueco así creado con resonancia posible, retro-pro-refleja, de un vacío en otro. Y Paul Klee recurría en pintura al negro de la luz en los negativos fotográficos. La imagen y el icono de escritura son luz filtrada en negro. A la percepción del objeto la subtiende un punto de oscuridad en el nervio óptico, también denominado mancha ciega. Imaginamos la realidad más de lo que creemos.

Incisión, agujero, vano —espaciamiento lineal—, manchas, tachones, búsqueda de un subfondo intuido a modo de proceso oculto, implícito, tapado, una efervescencia cuyo punto es el comienzo — «el comienzo surge a cada instante» (Sánchez Robayna, 2002: 14)—, el ahora y aquí del instante efectivo de escritura: Am Anfang... Pero en ese instante se oye La otra voz, dice Octavio Paz (1990: 133), la «de la diferencia original» — léase, la ontológica de Heidegger—, producida, como la impersonalización poética de Eliot, en el trasfondo de la historia. Ahora bien, esta figura del yo despersonalizado o histórico engendra otro tejido de reflejos múltiples o segunda naturaleza retórica del objeto-Libro, su imagen desplegada. La desaparición, muerte, vacío del Yo son figuras de un Ego temático con aspiraciones de estatua, relieve, museo, cuadro, partitura que lo identifiquen. Y mientras se niega el ser que posibilita el acto mismo de negación, la escritura se convierte en pódium y faro del propio ejercicio. Tal vez sea esto resultado de una metapoesía que no comprende realmente el vuelo interno que el lenguaje despliega en y sobre sí como conciencia. De ello derivan obsesiones como la del palimpsesto o el misreading del criticismo norteamericano. Cada línea borra el subsuelo que la sostiene y engendra. De ahí procede también la confusión, bastante común, de las implicaciones latentes en las unidades métricas con borrado o sobreañadido retórico. Mallarmé vio el efecto continuo de nominación en niveles gramaticales implicados dentro del verso como unidad dicente: «Le vers qui de plusieurs vocables refait un mot total, neuf, étranger à la langue et comme incantatoire, achève cet isolement de la parole» (Mallarmé, 1945: 368). Una palabra extraña, se entiende, a la lengua reducida a funciones elementales. En poesía, hasta el trazo de escritura retiene el infinito, porque el lenguaje tiende lazos a distancia, en la ausencia. Imprime huellas evocando, sugiriendo : «car méditer, sans trace, devient évanescent» (Mallarmé, 1945: 369). El poeta francés conoce las redes semánticas y los campos conceptuales que unen y entretejen, con nuevo arte combinatorio, los vocablos entre sí, entramados: «Ce pli de sombre dentelle, qui retient l'infini [...] assemble des entrelacs distants où dort un luxe à inventorier, stryge, noeud, feuillages et présenter» (Mallarmé, 1945: 370). 
Al principio, el punto expansivo también retráctil de la forma. Por eso la presencia en la poesía de Sánchez Robayna de otros términos típicos y plegados entre sí como «sombra», «vacío», «cero» y «nada», el intersticio del signo y símbolo histórico — Sobre una confidencia del mar griego $(2005)^{7}$ — o la obsesión negra del trasfondo al que revierte la ascensión posible: aire, nube, cielo, sol, aurora, ave, palma, etc. Con una concreción pétrea de silencio — piedra, roca- o vanamente circuida: ola, arena, mar, isla. El oleaje batido o sereno de la nada bajo el crepitar de lo visible que es, en el caso de este poeta, reducción del sonido a mirada o visión sonora de lo invisible — «El arte es un modo de mirar», dijo Marcel Duchamp_-, pretende ser hasta canción imposible compuesta sobre la línea articulada del habla coloquial, como una sucesión metonímica del aire espirado en sintagmas reflejos: «No es nada. Es solamente...». No ser que es y ser nadificado. Misión imposible: «No quieras saber algo en nada» (Sánchez Robayna, 2010: 153; 177). El signo flota en el vacío del habla inconsustancial, alienada. «No es nada» significativo —entendemos-, solo minucia. Lo mínimo del estar circuidos intentando el salto fuera del círculo, de la isla.

El tono injuntivo de estos poemas nadificantes es ya el habla sentenciosa que el poeta pliega y despliega sobre sí con la figura de un tú interpelado que es el yo en el binomio yo-objeto (mundo) antes citado. Retroproyección narcisista y espejismo de escritura singularizada. Un yo procesual y polarizado en el vaivén reflejo de referencias culturales y glosas renovadas ${ }^{8}$. El poema sigue siendo relieve o inscripción labrada a modo de estela, icono, lápida, camafeo o memoria de vida. Un mundo vital (Lebenswelt fenomenológico) crepitante: el reflejo lumínico de escritura. Hasta la nada refulge en el lenguaje que la dice. El sonido iluminado, la luz sonora, fono y fotón. Un mundo entrevisto en el lenguaje desde Herder, Humboldt, Hegel, Hölderlin y advertido por Heidegger en el primer tercio del siglo XX.

Resultado de esto es la ampliación del paradigma léxico en los poemas descriptivos. La búsqueda de la raíz nominal — el nombre de los nombres - apenas sobrepasa la intención. Describe el trasfondo intuido, pero no es, creemos, fuente de origen. Las palabras anuncian el comienzo que las incita y mantienen el impulso como índices suyos o deixis entrevista: ahí, aquí, ahora, en tales puntos del proceso. Mi posición es relato suyo — relación expansiva o retráctil—, noticia afectada donde mido el espacio-tiempo del movimiento circuido, parece decir una voz adjunta al relato. Es el final de la reflexión agustiniana sobre la moción perceptiva de la vibración interna incursa en la sensación-emoción del tránsito vital. Pero en la poesía comentada, de múltiples referentes y exégesis, la palabra cumple su esquema analógico, mientras que san Agustín lo trasciende. El creador, dice este santo (1991: 372), no habla en el alma de las cosas y de las criaturas ni «por lengua de carne, ni por voz de ángel, ni por sonido de nubes, ni por enigmas de semejanza». Refiere un remonte del alma sobre sí sin pensarse: «et ipsa sibi anima sileat et transeat se non se cogitando». Un sobrevuelo. Estas experiencias de intuición creadora dejan impreso un sabor especial en las palabras. Significa

\footnotetext{
${ }^{7}$ Es libro ilustrado por Antoni Tàpies y título integrado luego, con el de Correspondencias, que lo precede, en La sombra y la apariencia (2010: 73-111, 47-69, respectivamente).

${ }^{8}$ La edición inglesa, bilingüe, de El libro, tras la duna (The Book, Behind the Dune) (2017: 124-125), muestra al final 77 referencias intertextuales. Índice evidente del diálogo interno de esta escritura con una selección poética intencionada.
} 


\section{Antonio Domínguez Rey}

más lo que callan que lo hablado, el decir que lo dicho, en términos levinasianos, lo infado que lo fado, matiza Ortega.

Sánchez Robayna es consciente de esta distancia crítica y de su efecto retórico postmoderno. Por eso se aleja del entorno artístico alienado por la imagen banalizada con declaraciones críticas a veces tajantes. Este alejamiento le procura otra proximidad más afín, intimada, electiva, como la de poetas, pintores, filósofos, críticos anteriormente mencionados y otros que pudieran serlo, como los novelistas Juan Goytisolo y Julián Ríos. A este trasfondo poético añade la imagen medieval de la «nube del desconocimiento» que trascendió con diversas figuras retóricas posteriores (Santa Teresa, san Juan de la Cruz), como en el poeta canario con la nube del «no saber» (Sánchez Robayna, 2002: 22, 78, 90). Una ignorancia conceptual no obstante clarificadora de emoción y sentimiento. Es trasunto socrático de una exégesis en principio bíblica y que originó, con el tema de la ausencia de Dios, una teología negativa y otra superlativa. San Pablo ya se refiere al mundo inalcanzable del espíritu divino con la imagen de una «luz inaccesible» (1 Timoteo 6, 16). Tal nube aún es en Sánchez Robayna correlato objetivo de objetos circunstanciados, de imágenes sintéticas o lecturas motivadas a modo de principios objetivadores y sinérgicos del lenguaje. El poema LXXVI de El libro, tras la duna subsume la imagen de la Resurrección con deseo salvífico transformada «nuestra ceniza» en «una nube cernida sobre el mar» (Sánchez Robayna, 2002: 114). Huellas filtradas de la tradición analógica. La nube es símbolo en la Biblia de voz trascendente y frontera de lo inteligible. El texto antes citado de san Agustín ya advierte el giro de esta manifestación cosmológica hacia la visión interna o insight del alma.

\section{Impresión reverberante de mundo}

En este tipo de poesía correlatada, presente también en otros poetas contemporáneos, hay, sin duda, una tendencia al insight o visión intuitiva de las cosas, pero el carácter reductivo y plástico del lenguaje desliza también rasgos de marketing cultural y psicológico aplicados a la retórica poética como síntesis de percepción, entendimiento y conocimiento. El resultado es la apariencia esencial con rastro de sombra, oculta o patente. «Les objets, dès son apparition, se portent réciproquement ombrage. Portent leur ombre les uns sur les autres», afirma Ponge (1999: 784) en consonancia con Levinas. Se produce, no obstante, un fenómeno implícito revelador. El espejismo fónico de luz sonora es onda elicitada del sonido natural con tono y tempo especiales. Asimismo, la imagen plástica del lenguaje pliega el dinamismo espontáneo y visionario de la sensación inmediata. El sonido deviene icono y su reflejo abre, al vibrar ya como ausencia de algo que fue, una dimensión de resonancia proyectiva y objetivante. Los principios de un posible fundamento inducido remiten entonces a otras posibilidades aún inéditas de origen. El lenguaje renueva de este modo su energía latente. La onda del sonido y el pliegue de imagen — fotón interno - ya son partículas o formantes de una correlación irradiada de remisiones y «orden implicado», con denominación de David J. Bohm. En la retroproyección se produce lo que este físico entiende por reomodo, la fluencia verbal 
del nombre en el flujo real y ontológico del mundo (Bohm, 2002: 78). Y ese manantial fluyente lo percibimos también en el proceso de significación poética. Sucedería lo mismo en el universo semántico de la poesía según aplicación por Eloísa de Guzmán Alonso de esta idea y del concepto cuántico de «doble hendidura» a parámetros comunes de formas poéticas, físicas y musicales en combinación con las ondas brownianas (2017: 51-52).

En la poesía de Sánchez Robayna la elipsis verbal otorga relieve a la acción sintagmática que agrupa, correlaciona los nombres y combina los semas en orbes semánticos, conceptuales, icónicos, con sus valores sensibles acumulados. El poema ya es entonces el verbo propio. Las palabras despliegan el verbo que llevan dentro y se convierten en morfemas de la acción poética. Esta función la desempeña a veces el título sobre el conjunto del poema.

Vieja aspiración humana. En el principio era el verbo, la fluencia creadora. El orden holonómico — verbo de todo nombre - es verdaderamente cuanto de acción poética. El verbo sintetiza, digamos, lexema nominal, escena comunicativa — pronombres - y proceso objetivante. Al elidirlo, la síntesis acumula tensión verbal latente. Superpone en unidad dicente lexema, morfemas, esquema intersubjetivo, moción conceptual, modalidad fonológica según adhesión del sujeto hablante al mundo en el que se halla inscrito, y en virtud de un gramma emergente singular. Octavio Paz (1970: 18) entrevió esta correlación como «nueva analogía» ${ }^{9}$, probablemente leyendo a Roman Jakobson, a quien explicita con frecuencia en sus ensayos, entre la estructura alegórica de la lingüística y la subatómica, ambas reflejadas «en la clave genética». El químico y lingüista Ángel López García edujo efectivamente la homologación de los principios gestálticos que estructuran el lenguaje y la base genética del hombre partiendo de «un estrato innato común» (2002: 126). Del proceso intercelular del cerebro, activado por el genoma, derivan, según este autor, las conexiones extracelulares del lenguaje (2005: 173). Con otras palabras, pero semejante intención, intuyó Eliot esto mismo, recuerda Daniel Albright (2006: 279), al comparar la catálisis del ácido sulfúrico mezclando oxígeno y dióxido de sulfuro en presencia de un fragmento de platino con la despersonalización de la mente del poeta al transmutar sensaciones y pasiones: «The mind of the poet is the shred of platinum»(Eliot, 1980: 41).Y si aplicamos a esta homología la intuición epistemológica que subyace en las investigaciones de la física cuántica, necesitada de una renovación léxica continua y de imágenes sintéticas proyectivas, observamos que el acto de nominación sigue siendo gramma o impresión reverberante de mundo en la conciencia como forma cognoscente. Un arte combinatorio. Cada formante del poema funciona unísono y homólogo de onda y partícula, resume Albright su noción de Quantum Poetics (2006: 19). El flujo sonoro se condensa articulado y se objetiva con singularidad concreta. La forma verbal fusiona ondas fónicas fisionando partículas gramaticales a su vez concentradas como categorías cognoscitivas. Así procede la fusión unitaria y la fisión expansiva — descripción, relato— de Sánchez Robayna.

\footnotetext{
9 «La nueva analogía (Fragmento)» es capítulo del libro Los signos en rotación y otros ensayos (1986: 253-262), texto escrito y firmado en Delhi el 8 de mayo de 1967. Forma parte, casi entera, y a partir de la página 16, del texto inglés: The New Analogy. Poetry Painting and Technology (1970).
} 
Esta alternancia dentro de una moción unitaria de concepción mental, escritura, pintura o cálculo, es un parámetro cognoscitivo. Desde Aristóteles, Porfirio y Port-Royal, la tradición lógica medieval cifró su raíz - con ramificaciones hasta la semiótica de Charles Sanders Peirce - en dos modos del conocimiento: la comprehensio o conjunto de notas esenciales de un concepto, y la extensio, su ramificación singular y atribuible a los entes designados. En la tradición oriental existe un proceso semejante: la «unidad de coherencia» (k'ai-ho) a través de dos inflexiones. Una, concentradora ( $\left.k^{\prime} a i\right)$, y otra expansiva $(h o)$, pero ambas a partir de un trazo, punto de inicio (ch'i) o principio básico de abstracción rítmica, del que resulta el relacional indicado (Rowley, 1947: 48; citado por Jacques Maritain, 1953: 396). Es el fundamento gnoseológico de relaciones lingüísticas como las de hiperonimia e hiponimia, así como, más profundas, y semántico-lógicas, de oposición sémica entre nombres o de su estructuración en agrupamientos de campos léxicos y conceptuales. La tensión de un centro conceptual o léxico y referencias en él circuidas, como una concentración nominal de atributos, resulta evidente en la poesía de Sánchez Robayna. La comprehensión nominal y la extensión narrativa se interrelacionan mutuamente por la intensión creada al superponerse espacio y tiempo en unidad de acción poética. La palabra mantiene esta tensión interna en bucle de retroalimentación o autopoiesis emergente. Por eso se habla de poesía esencial, pero, para nosotros, y en interpretación crítica poética, este fenómeno es cifra de transición existencial reflejada por el factor prepositivo ex, de variado trasfondo simbólico, que subtiende la consistencia - sistere: exsistentia - escritural del poema como objeto u objeu, en la acepción de Ponge.

El lenguaje es retroproyectivo por naturaleza. Proyecta más allá de sus estructuras. Dice algo más que los procesos del texto génético: replicación, transcripción, traducción y transferencia, el mecanismo «3T+R» de López García (2002: 31; 106). Tres de ellos son homólogos de los principios de la Gestalt o teoría de la forma: ley de equivalencia, la transcripción; ley de clausura, la traducción; ley de proximidad, la transferencia. Es decir, para el caso que nos ocupa, y respectivamente, el trazo de escritura y pintura — correspondencia de artes, símbolo del poema como palimpsesto_, su trasunto de rasgos y la adjunción léxica, semántica. Y el otro proceso, la replicación, es el sintáctico del lenguaje, su proyección sintagmática. Estas cuatro funciones operativas y de la percepción las observamos también, por lo expuesto, en la poesía aquí estudiada. Y el plus — signo más (+) de la fórmula antes indicada - simboliza el sentido que conforma significados, cuyos bordes conceptuales no son discretos y reductivos como los computados digitalmente. Existen también ondas semánticas. Y éstas se perciben claramente en poesía: fonosemas, anagramas, isotopías, couplings, hendíadis, quiasmos, rima, ritmo, aura, etc. El lenguaje significa además de informar y transferir energía física y psíquica. En él se basa la gran metáfora del Libro como símbolo de estructura cósmica, desde la Biblia hasta Mallarmé y la gramática del Texto.

Este fenómeno comporta, sin embargo, la abertura de un horizonte en el todo de compleción que implica como fundamento explicativo, el horizonte poético de la «nube» y la «duna» aludido en el título de este estudio. «Nube»y «duna» sintetizan simbólicamente la polaridad interna del espaciotiempo abierto como escritura en la poesía de Sánchez Robayna. Esa dimensión funciona como 
engarce visual, poético y pictórico del poeta. Y es cifra además de la contingencia humana y de un resto existencial. A ambos fenómenos naturales los engarza un viento de cuya visibilidad es solo forma. La arena resulta también del soplo y movimiento del agua marina, de la lluvia potencial de las nubes, o es alzada, como ellas, y transportada por el aire a latitudes lejanas. Y en forma de «ceniza», cúmulo o «duna» de resto humano, cubre el horizonte como «una nube cernida sobre el mar», según veíamos antes (Sánchez Robayna, 2002: 114). Hay un móvil incurso en el desplazamiento y concentración de elementos. Por distantes que sean las formas de la naturaleza, como las palabras, unas de otras, las correlaciona una gramática interna, un gramma poético. Actúa siempre un factor implícito o un rasgo formal que nos traslada de una entidad a otra, o a un espacio-tiempo posible. Así acontece en la formación de la palabra al asociar un lexema, morfemas de inflexión, declinación, derivación, metafonía, tonos variados, timbres singulares, intensidades fonológicas con aura musical de ritmo emotivo. Y este fenómeno transcribe, traduce, transfiere un clima intelectual diferenciado. Induce una rotación interna en la cohesión de rasgos semánticos y replicación de sintagmas.

Observemos en esto el valor cognoscitivo de la forma poética. La poesía desentraña la vibración del conocimiento. La totalidad implicada no se recubre sin ranuras, rendijas, salidas de sí —electrón y gen centrífugos, capaces de reproducir en otro ámbito el circuito de origen-, poros de respiración renovada. Hasta la duna y la nube recomponen continuamente sus formas, como entrevió Haroldo de Campos en la poética bíblica sintetizando la rotación de elementos y esquemas lingüísticos. La replicación o la redundancia del lenguaje no permiten resquicios si no hay un germen implícito de diferencia integrada. Y la integración del lenguaje es retroproyectiva, posibilidad constante de nuevo germen, nunca el mismo, aunque haya espectros de igualdad sintáctica. El gramma poético es impresión de realidad vibrada en el cerebro e induce perspectiva inmediata, o mediada de configuración verbal. Crea inherencia de forma (Domínguez Rey, 2014: 32). Y el sentido inherente así conformado refuerza el carácter objetivo, u objeu, del poema. Su espontaneidad es cualificación cuántica o proceso de elementos superpuestos en función conceptiva creadora. El cuanto del lenguaje se potencia en la sílaba métrica por efecto de ritmo implicado. Recordemos la subsunción en el verso, según Mallarmé, de muchos vocablos como palabra total. Y así todos los formantes del poema. Por eso la importancia de abrir cauces al sentido siempre nuevo y responsable de existencia.

\section{Bibliografía}

Agustín, San (1991): Obras completas, II. Las confesiones. Madrid, B. A. C.

Albright, D. (2006): Quantum Poetics. Yeats, Pound, Eliot, and the Science of Modernism. Cambridge University Press, New York.

AleIXANDRe, V. (1974): Diálogos del conocimiento. Barcelona, Plaza-Janés.

BoHM, D. J. (2002): La totalidad y el orden implicado. Barcelona, Kairós.

CAmpos, H. DE (1981): Deus e o Diabo no Fausto de Goethe. São Paulo, Perspectiva. 
(1984): "Tradução, ideologia e história”, en SimON, I. M. (coord.): “Território da Tradução". Remate de Males. Campinas, Instituto de Estudos da Linguagem, pp. 239-247.

Domínguez ReY, A. (1985): «Luz y mirada en la poesía de Andrés Sánchez Robayna», Ínsula, ${ }^{\circ}$ 462, pp. 5-6. (Comentario de La roca).

(1986): «Lectura crítica de una poética», Ínsula, n 479, Octubre, p. 8. (Comentario de La luz negra. Ensayos y notas, 1974-1984).

- (1987): Novema versus povema. Pautas líricas del 60. Madrid, Editorial Torre Manrique Publicaciones.

- (1988): «Tiempo ubicuo. El texto plástico de Andrés Sánchez Robayna», Revista de Occidente. Las psicosis, no 88, septiembre, pp. 140-145. (Comentario de Poemas, 1970-1985).

- (1990): «Cavada luz», El Independiente, 15 marzo 1990, p. 7. (Reseña de Palmas sobre la losa fría).

- (1991): «Paratexto y clima fonémico (Primera poesía de Andrés Sánchez Robayna)». Homenaje al Profesor Sebastián de la Nuez. Universidad de La Laguna, pp. 345-360. (Comentario de Clima).

(1993): «El foro del signo», Diálogo de la Lengua. Cuenca, Instituto Juan de Valdés, pp. 144150. (Comentario de Fuego blanco).

- (2014): El gramma poético. Germen precientífico del lenguaje. Barcelona, Anthropos.

Eliot, T. S. (1980): Selected Prose. Ed. F. KeRModE. London-Boston, Faber and Faber.

GuZMÁn Alonso, E. de (2017): Convergencia de parámetros lingüísticos y musicales de poética.

Tesis doctoral. Madrid, Departamento de Lengua Española y Lingüística General, UNED, 29 de junio, $379 \mathrm{pp}$.

HAmAnN, J. G. (1999a): «Aesthetica in nuce», en Sämtliche Werke. II. Band. Schriften über Philosophie / Philologie / Kritik, 1758-1763. Tübingen, R. Brockhaus Verlag Wuppertal, pp. 195-217.

- (1999b): «Metakritik über den Purismus der Vernunft», en Sämtliche Werke. III. Band. Schriften über Sprache / Mysterien / Vernunft, 1772-1788. Tübingen, R. Brockhaus Verlag Wuppertal, pp. 281-289.

LEVINAS, E. (1994): «La réalité et son ombre», en Les imprévus de l'histoire. Fata Morgana, Montpellier, pp. 123-148. (Primera edición en 1948: Les Temps Modernes, $\mathrm{n}^{\circ}$ 38, novembre, pp. 771-789).

LÓPEZ GARCÍA, Á. (2002): Fundamentos genéticos del lenguaje. Madrid, Cátedra. (2005): The Grammar of Genes. How the Genetic Code Resembles the Linguistic Code. Bern, Peter Lang.

Maldiney, H. (2012a): « Notes sur le rythme», en Henri Maldiney : Penser plus avant..., Actes du Colloque de Lyon (13 et 14 Novembre 2010). J. P. CHARCOSSET, ed., París, Les Éditions de la Transparence, Éditions du Cerf, pp. 17-22.

(2012b): «Rencontre et ouverture du réel», en Ibíd., pp. 23-35. 
Mallarme, S. (1945): Euvres complètes. París, La Pléiade, Gallimard.

MARITAIN, J. (1953): Creative Intuition in Art and Poetry. New York, Pantheon Books.

MichauX, H. (1963): Plume, précédé de Lointain intérieur. París, Gallimard.

ORTEGA Y Gasset, J. (2005): «El espíritu de la letra», en Obras Completas. Tomo IV - 1926/1931.

Madrid, Santillana Ediciones Generales y Fundación José Ortega y Gasset, pp. 115-192.

PAZ, O. (1970): The New Analogy. Poetry Painting and Technology. Institute of Contemporary Arts.

Traducción de D. GARDNER. 3rd Annual Herbert Read Lecture, October 26. The Institute of Contemporary Arts. London, Nash House.

(1986): «La nueva analogía (Fragmento)», en Los signos en rotación y otros ensayos. Madrid, Alianza Editorial, pp. 253-262.

(1990): La otra voz. Barcelona, Seix Barral.

Ponge, F. (1999): Euvres Complètes, I. París, La Pléiade, Gallimard.

Rowley, G. (1947): Principles of Chinese Painting. New York, Princeton University Press.

SÁnchez Robayna, A. (1978): Clima. Barcelona, Llibres del Mall.

(1983): Tres estudios sobre Góngora. Barcelona, Llibres del Mall, Barcelona.

(1984): La roca. Llibres del Mall. Barcelona, Sèrie Ibèrica. Barcelona. (Premio de la Crítica, 1985).

(1985): La luz negra. Ensayos y notas, 1974-1984. Madrid, Ediciones Júcar.

(1987): Poemas, 1970-1985. Barcelona, Llibres del Mall.

(1989): Palmas sobre la losa fría. Madrid, Cátedra.

- (1992): Fuego blanco. Barcelona, Biblioteca Àmbit.

(1999): Inscripciones. Madrid, La Palma Editorial.

(2002): El libro, tras la duna. Valencia, Pre-Textos.

(2005): Sobre una confidencia del mar griego, precedido de Correspondencias. Madrid, Huerga y Fierro Editores.

- (2008): Deseo, imagen, lugar de la palabra. Madrid, Galaxia Gutenberg.

- (2010): La sombra y la apariencia. Barcelona, Tusquets.

(2017): The Book, Behind the Dune. Prefacio de Y. Bonnefoy. Traducción de L. Bourne.

Bristol. Shearsman.

SARTRE, J.-P. (1948): Qu'est-ce que la littérature? París, Gallimard.

(1964): Les mots. París, Gallimard.

(1986): Mallarmé. La lucidité et sa face d'ombre. París, Gallimard.

Wordsworth, W. (1999): El preludio (1779). Traducción de F. GALVÁn y A. SÁnchez RobAYnA.

Santa Cruz de Tenerife, Taller de Traducción Literaria. 